\title{
Socio-psychological barriers in higher inclusive education
}

\author{
Marina Skuratovskaya ${ }^{1 *}$, Inna Volodina $^{1}$, Larisa Kobrina $^{2}$ and Nadezhda Manohina ${ }^{1}$ \\ ${ }^{1}$ Don State Technical University, Rostov-on-don, Russia \\ ${ }^{2}$ Pushkin Leningrad State University, St. Petersburg, Russia
}

\begin{abstract}
Higher education is one of the conditions of independent life for disabled people, a condition of their social and labor rehabilitation. Health problems are not the only serious obstacles to vocational education. No less important are the barriers in the educational environment of the University and barriers in relationships with others. It is noted that most of the difficulties in the learning process of students with disabilities are associated with their psychological characteristics - the presence of negative experiences and attitudes, the level of self-esteem, the features of life orientations. Depending on the severity of psychological characteristics, different variants of the relationship of students with disabilities with other students are possible: from full integration to disintegration and opposition behavior. It was suggested that the nature of the relationship and especially value-semantic readiness for vocational education in higher inclusive education can largely determine the prospects of personal and professional development of students with disabilities. An empirical study of peculiarities of value orientations of students with disabilities $(\mathrm{N}=50)$ and students without disabilities $(\mathrm{N}=50)$ was conducted using the technique of G. N. Kuznetsova on the General self-identity, self-esteem scale of Rosenberg and test of life-meaningful orientations D. A. Leontiev.
\end{abstract}

\section{Introduction}

The system of higher education for persons with disabilities in Russia is undergoing significant changes. The changes are related to the work on the special organization of the educational environment in Russian universities for teaching disabled people. After all, without it for many students with disabilities higher education becomes inaccessible. This thesis is confirmed by the data of the all-Russian monitoring. In Russia, students with disabilities make up only $0.38 \%$ of all students. And only about half of the people with disabilities enrolled in the University successfully graduate. (Kurbangalieva E. S., Veretennikov D. N. [1]). This situation makes clear the special relevance of the issues

\footnotetext{
${ }^{*}$ Corresponding author: marinasku@yandex.ru
} 
of accessibility of higher education for citizens with disabilities. Higher education is one of the conditions of independent life for disabled people, a condition of their social and labor rehabilitation. Therefore, the criterion of accessibility becomes one of the key in assessing the educational environment of the University at the present time. In organizing the educational environment of the University, it is important to understand the nature of the difficulties faced by young people with disabilities in obtaining higher education.

The transition from the medical model to the social model in the understanding of disability allows us to understand the nature of some of the barriers to vocational education and further social and labor rehabilitation of people with disabilities. In the social model of disability, it is not only health problems that are serious obstacles to vocational education. No less important are the barriers in the educational environment of the University and barriers in relationships with others (Martynova E. A., Romanenko D. F. [2]).

E. A. Martynova highlighted the contradictions of social and pedagogical nature of different levels, preventing the creation of conditions of accessibility of higher education for people with disabilities (Martynova E. A.[2]). Among them, at the micro level, she identified the disparity between the physical, spiritual and social capabilities of persons with disabilities. This discrepancy becomes a barrier when the educational process does not take into account the individual characteristics of a student with a disability. According to the author, the contradiction of the meso level is connected with the existing barriers in the relations between students with disabilities and the University community, as well as with the existing barriers in the educational environment of the University (architectural accessibility of the University premises, availability of special programs and technical means of receiving and transmitting educational information, etc.). At the macro level, it is a mismatch between the higher education system and the needs of the country's social development. This contradiction prevents the implementation of such functions of higher education as integrating, socializing, professional and humanistic.

Considering the contradictions of the meso level, it should be noted that despite the importance of overcoming environmental barriers, one should not underestimate the importance of socio-psychological barriers. After all, the nature of communication with others largely determines not only the well-being of a person, but also the attitude to the activities that are associated with this communication. For a student it is an educational activity. This is especially important for young people with disabilities, who may experience difficulties in learning and communication due to the peculiarities of their psychophysical development.

As we have already noted, one of the reasons for the barriers in the relations of students with disabilities with others is still prevailing in society medical model of understanding disability. Within the medical model, the understanding of disability is perceived as pathology, the opposite of "health", "normality". Accordingly, the attitude to persons with disabilities is built according to the scheme: violation in developmentdisabled-defective. A young person with a disability cannot help but feel this attitude, even if it is not expressed openly. This leads to the isolation of the disabled student within the microsocium, violates his social integration. At the same time, the process of social integration is associated with adolescence. This age is characterized by the desire for unity, social recognition, inclusion in the social community. (Skuratovskaya, M. L., Klimova, T. V., Volodina, I. S. [3]).

In this respect interesting seems the approach of V. A. Palen, who proposes to consider the disability as a life experience and discursive construction (Palen V. A. [4]). With this approach, a disabled student acts as a bearer of a certain distinction, a feature 
that is not necessarily seen as a limitation. Rather, this difference is a reflection of the diversity of ways of expressing ideas about the environment, creating and transforming "their" world. And the University community alone includes various, equal mikrosotsium, including students with disabilities.

In L. I. Akatov's approach the success of inclusion of students with disabilities in the system of higher education is considered from the position of rehabilitation activity (L. I. Akatov [5]). Social rehabilitation activity as a component of comprehensive rehabilitation is aimed at the holistic development of personality, social activity of students with disabilities, taking into account their psychophysical capabilities. The implementation of social rehabilitation activities assumes the presence of a specially organized educational environment at the University. At the same time, social rehabilitation activities should proceed from the fact that a student with a disability is a subject of education. And as a subject of education, he is able to independently make choices in educational and life situations and bear responsibility for his choice. This means that the special conditions that will be created in the educational environment of the University should take into account not only the existing limitations, but also the potential of the individual student with disabilities. This approach helps to overcome the dependent position of students with disabilities.

The nature of the choice of educational route is associated with the specific educational needs of students with disabilities. The study conducted by V. Z. Kantor among graduates of special schools revealed that the most pronounced need is the need for assistance of an assistant. On the second place according to the results of the survey was the need for special software and equipment to ensure the availability of reception and transmission of educational information, as well as the need for a special route organization of the accessible environment of the University. Then followed the need for adaptation of the educational program and socio-psychological support. At the same time, the author notes that the severity of certain specific educational needs is influenced by the nature of the existing violation (Kantor V. Z., Antropov A. P., Gdalina T. G. [6]). Similar data were obtained in the study of E. V. Vojvodina (E. V. Vojvodina, [7] ).

The basic principles of the organization of rehabilitation and educational environment of the University were developed in the Russian state pedagogical University named after A. I. Herzen (St. Petersburg). These include:

- orientation of rehabilitation and pedagogical activity on achievement of the purposes of professional education;

- orientation of the University teachers to achieve the goals of rehabilitation and social integration;

- taking into account the individual characteristics of the rehabilitation potential of a disabled student;

- the use of a complex of psychological, pedagogical, medical and social means to support students with disabilities;

- continuity of psychological and pedagogical support for students with disabilities at all stages of rehabilitation;

- active involvement of the student community in the process of psychological and pedagogical support of students with disabilities. (Cantor V. Z. [8]).

But the practice of creating a rehabilitation and educational environment indicates a different level of accessibility in Russian universities. According to the monitoring conducted by the Ministry of education and science of the Russian Federation in 2015 in 583 universities, conditions for training students with visual impairment were created in only $30.5 \%$ of universities. Students with musculoskeletal disorders could feel comfortable in $32.8 \%$ of universities. For students with hearing impairment, an 
accessible environment was created in $66.5 \%$ of universities. It was also noted that only $62 \%$ of universities had a position of psychologist for psychological and pedagogical support of students with disabilities. And only $34.8 \%$ of universities had assistant positions to help students with disabilities ([9]).

Returning to the issue of barriers in higher inclusive education, it should be noted that in some studies, most of the difficulties in the learning process of students with disabilities are associated with their psychological characteristics. These features include conflict, the desire to subordinate the time and effort of the interaction partner, the desire to simplify the solution of the problem at the expense of guaranteed assistance (Vovk V. N., [10]).

Depending on the severity of psychological characteristics (the presence of negative experiences and attitudes, the level of self-esteem, especially life orientations), there are different options for the relationship of students with disabilities with other students. It can be a full and versatile integration in all spheres of interaction of a disabled student with classmates and University staff. There can be integration only in the educational sphere, in which interaction is carried out only within the framework of educational activities and does not go beyond it. A variant of disintegration can be observed in cases where a student with a disability is isolated from others and his relationships in the University community are minimized. Finally, a variant of oppositional behavior is possible, in which the student consciously opposes himself to others on the basis of disability. Often this position has a hidden goal-to achieve leniency and concessions to themselves (Cantor VZ [11]).

There is no doubt that the nature of the relationship can largely determine the prospects for personal and professional development of students with disabilities. Therefore, it seemed important to study the features of their value-semantic readiness for vocational education in higher inclusive education.

\section{Methods}

The study involved 50 students with disabilities and 50 students without disabilities studying at the don state technical University. The students participating in the experiment were trained at different faculties and at different courses. The inclusion of these two groups in the experiment is explained by the desire to identify the specific features of value-semantic aspects of personal readiness for learning in higher inclusive education of students with disabilities compared with students without disabilities.

According to the nature of health disorders among the students participating in the experiment with disabilities, the largest group consisted of students with musculoskeletal disorders-18\% and visual impairment-15\%. The number of students with disabilities with somatic diseases was $14 \%$. The smallest group was students with hearing impairment $-3 \%$. About $50 \%$ of students with disabilities did not indicate the cause of disability.

As diagnostic techniques were used: the method of G. N. Kuznetsova on the General self-identity, self-esteem scale of Rosenberg and test of life-meaningful orientations D. A. Leontiev. All students participating in the empirical study filled out questionnaires and questionnaires.

\section{Results}

The content analysis of the hierarchical structure of the value orientations of the subjects revealed the priority of social motives. All students are characterized by the 
priorities of such values in relationships with others as self-confidence, tolerance, responsibility, which reflects a fairly Mature position. At the same time, the importance of such value orientations as intransigence to the shortcomings of others and high demands is reduced. This is obviously due to the gradual formation of a more serious, "adult" life position of students.

Significant for both groups of subjects were such meaning-life values as creativity and knowledge. The importance of such a value as a strong will was noted, which is also due to the nature of the tasks facing students during their studies at the University and the intensity of educational activities. At the same time, there was a tendency to reduce the importance of such characteristics as the breadth of views, which is associated, obviously, with the need to focus attention and effort on a certain area of knowledge in the course of vocational education.

There were also identified specific features of value orientations for the group of students with disabilities. Against the background of the commonality of the main directions of personal readiness for learning in higher inclusive education, students with disabilities noted uncertainty in the future, the increasing role of past experience. Such manifestations were the result of pessimism typical for young people with disabilities in relation to the manageability of life, its emotional saturation, meaningfulness. As a result of this uncertainty and pessimistically views on life, they revealed a lower motivation to self-development, compared with students without disabilities. Another identified feature was the priority of external activity in comparison with the manifestation of internal, mental activity. All this suggests that for students with disabilities is more typical adaptive orientation of relations, rather than individualization and integration into the educational environment of the University. Perhaps that is why for students with disabilities the most typical was the specific emotional (low) level of passive-positive orientation in the development of value-semantic components of personal readiness for learning in higher inclusive education.

\section{Conclusion}

The features of value orientations of students with disabilities identified in the study confirm the need to create special conditions in the educational environment of the University, taking into account their psycho-emotional and personal characteristics, the presence of special educational needs. It is very important that these conditions make relationships with others meaningful, contribute to the development of responsibility, activity and independence of a disabled student both in education and in socially important matters. One of the most important conditions can and should be an individual educational program of a student with a disability. The program should be aimed at solving a number of problems.

First, the successful development of the educational program as a basis for the professional development of a young disabled person. This task requires actualization of the student's personal potential. Psychological and pedagogical support here should be aimed at the prevention of psychological problems and the creation of pedagogical conditions that ensure the success of educational activities. These conditions imply, in particular, a significant degree of freedom in the educational process, free variation of classroom and extracurricular conditions of the educational route, depending on the state of health and educational needs.

Secondly, it should ensure the activity of the student in the construction of an individual educational program in the process of interaction with teachers, when choosing academic disciplines. The challenge here is to ensure that the levels of prior claims and actual achievements on knowledge and relationships do not vary greatly. 
Psychological and pedagogical support in this case should be focused on the choice of real goals and means to achieve them.

Third, the individual educational program should contribute to the development of emotional and value relations of disabled students with other students in the implementation of the educational program, overcoming difficulties, providing an opportunity for active communication with all participants of the educational process.

\section{References}

1. E.S. Kurbangalieva, D.N. Veretennikov, Psychological science and education 2017. 22(1). 169-180 (2017)

2. E. A. Martynova, D.F. Romanenko, Historical and social and educational thought. 4 (20), 98-102 (2013)

3. M.L. Skuratovskaya, T.V. Klimova, I.S. Volodina, Culture of tolerant interaction in the socio-cultural space of the University as a condition of accessibility of vocational education for disabled people (Rostov-on-don, 2013)

4. V.A. Palenny, Proceedings of the IV Moscow Symposium on the history of the deaf (Zagreus, Moscow, 2003)

5. L.I. Akatov, Social rehabilitation of children with disabilities (VLADOS, Moscow, 2003)

6. V. Z. Kantor, A.P. Antropov, T. G. Galina, Psychological science and education 23 (2), $42-49$ (2018)

7. E.V. Voevodina, Vocational education and labor markets. 4, 20-27 (2018)

8. V.Z. Kantor, Herzen University Bulletin, 10 (2008)

9. Certificate of availability in higher education institutions conditions for higher education for disabled (2015)

10. V.N. Vovk, Accessibility of higher education for the disabled: materials of the final international, 13-16 (2003)

11. V.Z. Kantor, International journal of experimental education, 7. 132-135 (2013) 